CAPONI, Sandra; VÁSQUEZ-VALENCIA, Maria Fernanda; VERDI, Marta. (Org). Vigiar e Medicar: estratégias de medicalização da infância. São Paulo: LiberArs, 2016.

\title{
Uma crítica da medicalização da infância
}

\section{A criticism of the childhood medicalization}

Ana Terra de Leon ${ }^{1}$

A produção de saberes não é imparcial. Atende e se motiva por interesses, sejam eles econômicos, políticos, religiosos, morais, ou de qualquer outro tipo. O saber é uma forma de exercer poder. E o poder se vale dos saberes em seu exercício. Relação recíproca, e que pode ser positiva, na medida em que produz coisas. Quais são as vozes autorizadas da normalidade? A que tipo de poder serve a produção de saberes médicos? Quais são as motivações da produção de verdade da psiquiatria?

Publicado no fim de 2016, "Vigiar e Medicar: estratégias de medicalização da infância”, livro organizado por Sandra Caponi, Maria Fernanda Vásquez-Valencia e Marta Verdi, com título de nítida inspiração foucaultiana, se propõe a refletir sobre essas questões e, mais que isso, propõe a crítica à forma como a psiquiatria vem, no ocidente, esquadrinhando os sujeitos e suas formas de viver, de se expressar, de se relacionar.

O título do livro evoca outra obra: "Vigiar e Punir", publicado em 1975 por Michel Foucault, em que o autor se dedica, para além do estudo das penas, a analisar uma constelação de saberes - médicos, jurídicos, filosóficos - que se reúnem, se engendram e se articulam na produção de verdades acerca da lei, da punição, da disciplinarização e controle dos corpos.

"Vigiar e Medicar", em contrapartida, analisa a proliferação de diagnósticos e a crescente medicalização da sociedade com foco na infância. Assim como em"Vigiar e Punir", de Foucault (mas nem sempre se aportando teoricamente nele), as autoras e os autores deste livro buscaram analisar crítica e pontualmente, de forma a propor soluções para o problema da mercantilização do sofrimento em saúde mental, apontando para os riscos ou, antes, para a efetividade questionável do diagnóstico e da administração de psicofármacos em crianças e adolescentes, fenômenos crescentes desde a década de 1990.

Apesar de reunir artigos de autores diferentes e que partem de pressupostos teóricometodológicos que diferem entre si em seus capítulos, "Vigiar e Medicar" é um livro bastante 
consistente. Porque parte de uma premissa crítica que aparece em todos os textos apresentados: a preocupação com a massificada prescrição de remédios e de diagnósticos psiquiátricos na infância. Se a psiquiatria se defende num discurso de avanço tecnológico e descobertas científicas que finalmente possibilitam que os chamados "transtornos mentais" sejam tratados além de mapeá-los e preveni-los já desde tenra idade, as pesquisadoras organizadoras deste livro reuniram nele uma série de análises que não apenas criticam a utilidade e a real motivação destas práticas médicas como também apontam para a ineficácia e para as fracas comprovação científica e elaboração epistemológica dos estudos farmacológicos dos psicofármacos e da comprovação de diagnósticos associada à psiquiatria da infância.

$\mathrm{Na}$ apresentação do livro as organizadoras tiveram o cuidado de fornecer ao leitor uma forma mapeada de ler a obra, o que facilita a leitura e a compreensão de como o grupo de autores e autoras do livro estavam pensando a estrutura do mesmo. São apresentados três eixos temáticos que abarcam os diferentes textos, apesar da obra não ser separada nessas partes ou subcapítulos, ou seja, não é subdividido, os capítulos apenas aparecem sequencialmente - os eixos aparecem mais como um guia de leitura.

O primeiro eixo, que foi chamado "O DSM e a proliferação de novos diagnósticos", traz textos que fazem sua análise girar em torno do Manual Diagnóstico e Estatístico de Transtornos mentais (o DSM), cuja sigla não aparece especificada num primeiro momento, só ao longo dos capítulos, o que pode confundir o leitor desavisado que não tenha qualquer conhecimento acerca dos temas abordados. Nesse primeiro eixo os autores e autoras discutem a influência do manual no diagnóstico dos transtornos mentais, notadamente os da infância, e analisa a crescente vertiginosa do número de transtornos de um volume para o outro, notadamente o último, o DSM-5.

No segundo eixo, "A medicalização da infância em perspectiva histórica", temos acesso a uma discussão acerca dos crescentes processos de controle da infância aportada na análise histórica dos transtornos mentais da infância a partir de teses, manuais de diagnóstico, estudos estatísticos e outras fontes.

No terceiro e último eixo, intitulado "Ética, indústria farmacêutica e medicalização da infância", a crítica se fecha um pouco mais nas questões mercadológicas referentes à

\footnotetext{
1 Mestranda, Programa de Pós-Graduação em História da UFSC, bolsista CAPES. E-mail:
} anatdeleon@gmail.com 
produção de saberes psiquiátricos acerca da infância e da adolescência e as implicações éticas da influência da indústria farmacêutica nesse processo de medicalização.

A construção de saberes não é imparcial. Obedece a estruturas próprias e serve a determinados poderes. O livro "Vigiar e Medicar" o demonstra bem, articulando fontes e dados precisos e crítica certeira dos usos feitos recentemente da psiquiatria e da farmacologia para o controle social desde a infância. Se nenhum saber é imparcial, também o livro aqui analisado não é - marca sua posição frequentemente em todos os capítulos. Certamente todo livro produzido dentro das Ciências Humanas possui um determinado posicionamento, mesmo que seja do ponto de vista metodológico. No entanto, poucos livros - porque poucos autores - se colocam politicamente de forma tão assertiva e crítica.

"Vigiar e Medicar: estratégias de medicalização da infância" aponta uma necessidade urgente de mobilização social e de análise científica dos fenômenos que aborda. É um livro que contribui com o embasamento da atuação política de qualquer cidadão crítico das políticas públicas de saúde mental, e coloca o meio acadêmico a serviço de todos os setores da sociedade, conversando com problemas que afetam-nos como um todo.

\section{Referências}

FOUCAULT, Michel. A Ordem do Discurso: aula inaugural no Collège de France, pronunciada em 2 de novembro de 1970. São Paulo: Edições Loyola, 2005.

Vigiar e Punir: nascimento da prisão. Petrópolis: Vozes, 1987. 